\section{Population genetics}

SiR - J.A. Shapiro (Nature 19 May, p.196) criticizes population genetics on two counts. First, he claims that "there is no evidence" that theoretical population genetics "has been successful in illuminating and explaining the process of biological evolution'. Second, he asserts that population geneticists "assume complex (and therefore troublesome) phenomena out of existence"; recently discovered genetic phenomena such as mobile elements are given as an example of this.

The first claim is truly astonishing in view of the many classic works documenting the close agreement between the phenomena of evolution and the expectations of population genetics ${ }^{1-6}$. The second ignores the efforts being made by population geneticists to model aspects of genome evolution, such as the evolution of multigene families ${ }^{7,8}$, the evolution of chromosomal structure ${ }^{9}$ and the population dynamics of mobile elements ${ }^{10-13}$. We could cite many other papers that show the eagerness of population geneticists to incorporate new discoveries in molecular genetics into their thinking. We hope that molecular biologists will admit the relevance of population thinking to interpretations of the evolutionary significance of their discoveries. BRIAN CHARLESWORTH

School of Biological Sciences,

JOHN MAYNARD SMITH

The University of Sussex

Brighton, Sussex, UK

1. Dobzhansky, T. Genetics and the Origin of Species (Columbia University Press, New York, 1937).

2. Huxley, J.S. Evolution, The Modern Synthesis (Allen and Unwin, London, 1942)

3. Mayr, E. Systematics and the Origin of Species (Columbia University Press, New York, 1942).

4. Stebbins, G.L. Variation and Evolution in Plants (Columbia University Press, New York, 1950).

5. Simpson, G.G. The Major Features of Evolution (Columbia University Press, New York, 1953).

6. Rensch, B. Evolution above the Species Level (Columbia University Press, New York, 1959).

7. Ohta, T. Evolution and Variation of Multigene Families (Springer, Berlin, 1980).

8. Nagylaki, T. \& Petes, T.D. Genetics 100, 315 (1982).

9. Lande, R. Evolution 33, 234

10. Ohta, T. \& Kimura, M. Proc. natn. Acad. Sci. U.S.A. 78, 1129 (1981).

11. Hickey, D.A. Genetics 101, 519 (1982).

12. Charlesworth, B. \& Charlesworth, D. Genet. Res. (in the press).

3. Langley, C.H., Brookfield, J.F.Y. \& Kaplan, N.L. Genetics (in the press).

\section{Advice on AIDS}

SIR - I have read with interest your editorials on AIDS and the ensuing correspondence. There is good evidence from animal experiments that contact with semen may promote immune suppression, and frequent anal intercourse may therefore be a causal factor in the immune deficiency characteristic of AIDS.

However, I know of no evidence incriminating promiscuity as such. Would it not therefore be more helpful to suggest that male homosexuals protect their partners by using condoms?

AnNe McLaren MRC Mammalian Development Unit, London NWI, UK

\section{Embryological elitism}

SIR - I would reverse your editorial writer's argument in the title, "Embryology needs rules, not new laws" (Nature 28 April, p.735) to state that the onset of human life needs new laws, not rules. Laws may be transient, but they are longer lasting than rules. Laws are made by people as opposed to rules which are made by an elite, usually for their own interest. The definition of the onset of human identity is not the decision of academic embryologists as your writer claims, but that of our legislators - the politicians, who are influenced by many opinions including religious authority, philosophy and scientists as well as their constituents.

When human life begins in development is a complex argument which is the battlefield of intransigent ideas and emotions. But it does not follow that these ideas and emotions are misguided any more than the concept that human life begins at parturition as if the discarding of the intrauterine environment and placenta somehow gives a freedom to express individuality and therefore personhood. It can be argued that it is only exchanged for the parasitism of parental support and protection which is just reason for denial of human identity according to your editorialist's supposition.

How can academic embryologists be superior to politicians and those who protect human life from conception when they must be influenced by the desire to gain knowledge from manipulation of the human embryo? If the embryo is denied identity or the potential for identity, it can be used in any way. Then there is no need for ethical committees except for consolation of "the general public"'so that it can be informed "after the event". Unlike embryology, the making of a definition of human life, in secular terms, belongs to "ordinary people" through the creation of laws.

Health Sciences Division,

J.J. MEENAN

Atomic Energy of Canada Ltd,

Chalk River, Ontario, Canada

\section{Just imagine . . .}

SIR - Ian Fells' derivation of expressions relating lethergy and exergy (Nature 14 April, p.566) inspires application of his approach to other fields. For example: progress has two components, (1) materialistic progress and (2) progress in a spiritual sense. As only the latter is associated with increase in genuine happiness, we can regard it as the real component of progress; materialistic progress on the other hand is the imaginary component.

Likewise there are two ways of arriving at the truth: (1) reasoning from axioms in accordance with previously laid down procedures of inference; and (2) arriving at the truth by use of man's higher intuitive abilities. The truths deriving from the former approach are inevitably ultimately superseded, and so they constitute the imaginary component of truth. The latter procedures on the other hand lead, ideally, to the real component of truth.

Cross-couplings between the real and imaginary aspects of life are weaker than those between real and real and between imaginary and imaginary, so that individuals or groups tend of ten to exhibit one of these aspects only, to the effective exclusion of the other. Reciprocal inhibition plays an important role here. In advanced civilizations there is a dangerous tendency for the imaginary aspects of life to take over and exclude the real (both aspects being necessary for the health of individual societies and of mankind as a whole).

The following is a typical set of processes within the system, that we discover when we examine the situation in detail: science and education play an important role in this cycle. If science and education emphasize the imaginary component of truth, then (it happens in practice) the discoveries which science unfolds tend to be ones which are related to the materialistic (imaginary) component of life, and the progress of society is accordingly largely in the imaginary direction. The loop closes by virtue of the fact that a materialistic society tends to emphasize the imaginary aspect of truth in its approaches to education and its approach to life.

An important reciprocal inhibition mechanism is the following: scientists (especially) are prone to condemn strongly (and with considerable emotion) any ideas which are predominantly products of the intuitive mind (notwithstanding the fact that scientists such as Einstein made great use of intuition as a means of seeing their way to the essential form of the truth, in advance of any possible justification of the outcome by rational means). My own experience leads me to infer the existence of a fundamental communication barrier; people trained to think only in terms of rational (imaginary) thinking processes may be quite unable to follow an argument which makes non-trivial use of intuition, such as the ordinary man in the street might be able to follow. Such are the results of educational conditioning. One visible result, for example, is the widespread disregard by the scientific community of the very significant work of Bohm ${ }^{1}$.

It is easier to indicate a problem than to suggest a solution. I have no simple one to offer. Perhaps this letter will have a sufficiently disturbing effect on the minds of a few readers that new, freer patterns of thought will emerge in their minds as a consequence; one can but hope this may prove to be the case.

Cavendish Laboratory

B.D. JOSEPHSON

\section{Cambridge, UK}

Bohm, D. Wholeness and the Implicate Order (Routledge and Kegan Paul, L.ondon, 1980). 